\title{
Desenhos que revelam o processo de adoecimento de mulheres usuárias de um CAPS- ad III
}

\author{
Drawings that reveal the illness process of women using a CAPS-ad III
}

DOI: $10.46919 / \operatorname{archv} 1 \mathrm{n} 5-020$

Recebimento dos originais: 10/07/2020

Aceitação para publicação: 30/08/2020

\author{
Ana Cláudia Afonso Valladares Torres \\ Enfermeira e Arteterapeuta. Doutora em Enfermagem Psiquiátrica. Docente da Universidade de Brasília \\ $(\mathrm{UnB})$ \\ Instituição: Faculdade de Ceilândia da Universidade de Brasília (FCE/UnB) \\ Endereço: Centro Metropolitano, conjunto A, lote 1 - Ceilândia Sul. Brasília, Distrito Federal - Brasil \\ E-mail: aclaudiaval@unb.br \\ Victória Helen Ribeiro Lima \\ Enfermeira. Residente de Saúde Mental, álcool e outras drogas \\ Instituição: Fundação Oswaldo Cruz de Brasília \\ Endereço: Av. L3 Norte, s/n, Campus Universitário Darcy Ribeiro, Gleba A, Brasília, Distrito Federal - \\ Brasil \\ E-mail: victoria.ribeiro836@gmail.com
}

\section{RESUMO}

Objetivo: Conhecer o processo de adoecimento, por meio do desenho "Metáfora da chuva" sob a ótica de mulheres dependentes de substâncias psicoativas que estavam em proposta terapêutica no CAPS-ad. Material e método: Trata-se de um estudo exploratório-descritivo com abordagem qualitativa a partir do desenho "Metáfora da Chuva", que contou com amostra de 28 mulheres usuárias de um Centro de Atenção Psicossocial-álcool e outras drogas III de Brasília/DF. As respostas dos dados do desenho foram submetidas a análise temática de conteúdo qualitativo do tipo temático estrutural. Resultados: Os dados foram agrupados em três grandes categorias, a saber: as causas da dependência de drogas; os impactos ou as consequências decorrentes do uso abusivo das drogas psicoativas; e o enfrentamento em relação à dependência de drogas. Foram elencadas, na categoria causas, seis dimensões ou problemas: psicológicas ou de comportamento; no relacionamento com a família; socioculturais; relacionadas à violência; biológicas ou físicas; e no trabalho, em um total de 86 respostas. Nas consequências ou os impactos, foram elencadas oito dimensões: psíquicos ou comportamentais; no relacionamento com a família; no trabalho; ou no aspecto econômico-financeiro; relacionados com a violência; na saúde física; socioculturais; com a educação ou nenhum problema, em um total de 112 respostas. Já na terceira categoria do enfrentamento emergiram duas subcategorias: uma negativa e outra positiva, em um total de 41 respostas. Conclusão: Os desenhos "Metáfora da chuva", desenvolvidos pelas mulheres, permitiram elucidar uma trajetória de vida subjetiva permeada por muitas fragilidades e vulnerabilidades pelo seu próprio protagonismo. A oferta de um espaço para o diálogo e a reflexão pelos profissionais de saúde, no sentido de proporcionar momentos de elaboração de experiências negativas, pode ser uma oportunidade de reconstrução de novos projetos de vida.

Palavras-chave: Terapia pela arte, Saúde mental, Transtornos relacionados ao uso de substâncias, Saúde da Mulher. 


\section{ABSTRACT}

Objective: To know the process of illness, through the design "Metaphor of rain" from the perspective of women dependent on psychoactive substances who were in a therapeutic proposal in the CAPS-ad. Material and method: This is an exploratory-descriptive study with a qualitative approach based on the drawing "Metaphor of the Rain", which included a sample of 28 women using a Psychosocial Care Center for alcohol and other drugs III in Brasília/DF. The responses to the design data were subjected to thematic analysis of qualitative content of the structural thematic type. Results: The data were grouped into three major categories, namely: the causes of drug addiction; the impacts or consequences resulting from the abuse of psychoactive drugs; and coping with drug addiction. In the causes category, six dimensions or problems were listed: psychological or behavioral; in the relationship with the family; socio-cultural; related to violence; biological or physical; and at work, in a total of 86 responses. In the consequences or impacts, eight dimensions were listed: psychic or behavioral; in the relationship with the family; at work; or in the economic-financial aspect; related to violence; in physical health; socio-cultural; with education or no problem, out of a total of 112 responses. In the third category of coping, two subcategories emerged: one negative and the other positive, in a total of 41 responses. Conclusion: The drawings "Metaphor of rain", developed by women, allowed to elucidate a subjective life trajectory permeated by many weaknesses and vulnerabilities due to its own role. The provision of a space for dialogue and reflection by health professionals, in order to provide moments of elaboration of negative experiences, can be an opportunity to reconstruct new life projects.

Keywords: Art therapy, Mental health, Substance-Related Disorders, Women's health.

\section{INTRODUÇÃO}

O uso abusivo de substâncias psicoativas tem-se tornado um problema mundial de saúde. A diferença entre o uso, abuso e dependência de álcool e outras drogas entre homens e mulheres tem reduzido ao longo dos anos, mas ainda prevalece no sexo masculino. Algumas características biológicas, psicológicas e psicossociais contribuem para a diferença com relação ao uso de álcool entre homens e mulheres, por exemplo, as mulheres têm $51 \%$ de água no corpo, quando os homens têm $65 \%$, o que resulta na diferença de concentração de álcool entre eles, sendo maior no corpo feminino, quando consumido na mesma quantidade ${ }^{(1)}$.

Outra característica feminina que contribui para maiores concentrações de álcool no sangue quando comparadas com homens é a menor quantidade da enzima responsável pela primeira fase de metabolização desta substância, a enzima álcool desidrogenase ${ }^{(1)}$. Portanto, essas diferenças tornam as mulheres mais vulneráveis à dependência e a agravos causados pelas substâncias psicoativas do que os homens. Diante dessa situação, faz-se necessário um atendimento profissional que ofereça assistência à saúde e às demandas psicossociais e interpessoais das mulheres dependentes de substâncias psicoativas.

Conforme o Relatório Mundial de Drogas do Estritório da Organização das Nações Unidas de Combate às Drogas e Crimes ${ }^{(2)}$, estima-se que, aproximadamente, 27 milhões de pessoas fazem o uso nocivo de drogas e mais de $10 \%$ dos usuários de drogas sofrem de transtornos mentais decorrentes do uso 
ou da dependência de drogas. Existem diversos estudos sobre a dependência de drogas e os transtornos mentais relacionados, todavia poucos focalizam as mulheres.

A assistência à saúde de indivíduos com transtornos mentais decorrente do uso de drogas é feita por meio da Rede de Atenção Psicossocial (RAPS), instituída em 2011, pelo Ministério da Saúde. A RAPS tem a finalidade de criação, ampliação e articulação de pontes de atenção à saúde para indivíduos em sofrimento mental e com transtornos causados pelo uso de drogas. Entre os componentes da RAPS, estão os Centros de Atenção Psicossociais (CAPS), pontos de atenção psicossocial especializada, constituídos por equipe multiprofissional que atua por meio da interdisciplinaridade e oferece atendimento às pessoas com transtornos graves e persistentes e àquelas com necessidades decorrentes do uso de drogas ${ }^{(3)}$.

Contrários aos hospitais psiquiátricos, denominados manicômios, que mantiveram os "loucos" isolados e marginalizados socialmente, os CAPS proporcionam e estabelecem relações consistentes com a comunidade $^{(4)}$. Com isso, os CAPS objetivam elaborar projetos de vida, de produção social e de promoção da qualidade de vida dos usuários. Entre as modalidades de CAPS, há o CAPS-álcool e outras drogas (CAPS-ad) III, que oferece assistência aos indivíduos com transtornos decorrentes do uso de substâncias psicoativas que necessitam de cuidados clínicos contínuos. Essa modalidade conta com leitos para observação e monitoramento, com funcionamento de 24 horas, incluindo feriados e finais de semana $^{(3)}$.

Os CAPS, nas suas diversas modalidades, oferecem atividades terapêuticas, consultas e terapia medicamentosa, e as psicoterapias individuais ou em grupo, oficinas terapêuticas criativas, atividades comunitárias, atividades de artes, orientação e acompanhamento do uso de medicação, atendimento domiciliar e aos familiares ${ }^{(1)}$. Entre as atividades artísticas, a Arteterapia que é uma prática integrativa e complementar que utiliza várias técnicas expressivas, como a pintura, o desenho, a dança, a dramatização, com finalidade terapêutica. O desenho em Arteterapia concretiza alguns pensamentos e exercita a memória, bem como está relacionado ao movimento e ao reconhecimento do objeto e tem a função ordenadora ${ }^{(5)}$.

Atualmente, há necessidade de propiciar espaços para a expressão e a reflexão do processo de adoecimento pelas mulheres dependentes de drogas por meio da arte, favorecendo a escuta ativa, a autonomia, bem como a inserção da criatividade no contexto da saúde mental, o que, por si só, justifica este estudo. Perante este cenário, pergunta-se: como abordar o processo saúde/doença com mulheres dependentes de drogas para que se possa compreender a complexidade e a subjetividade do fenômeno, usando estratégias de intervenção criativa e inovadora? Nessa perspectiva, esta pesquisa torna-se relevante por entender, por meio da arte, o processo de adoecimento, a partir da verbalização das 
mulheres e pode, dessa forma, contribuir para o desenvolvimento de atividades de cuidado no contexto da saúde mental e pautadas na criatividade e na ludicidade, a fim de subsidiar a reflexão desse grupo.

Diante do exposto, o objetivo geral desta pesquisa é conhecer o processo de adoecimento por meio do desenho "Metáfora da chuva" sob a ótica de mulheres dependentes de substâncias psicoativas que estavam em proposta terapêutica no CAPS-ad III. E como objetivos específicos: conhecer o perfil sociodemográfico, clínico e psiquiátrico, e, da mesma forma, investigar a prevalência de sintomas depressivos e ansiosos das mulheres participantes da pesquisa.

\section{MÉTODO}

Trata-se de um estudo exploratório-descritivo com abordagem qualitativa a partir do desenho “Metáfora da Chuva". Trata-se de um desenho projetivo, um instrumento de avaliação em saúde mental, elaborado por Angelim e Valladares-Torres ${ }^{(6)}$ e tem como foco central a elaboração gráfica de um lago, de nuvens e da chuva em um desenho único. O desenho estimula o diálogo (verbal e/ou escrito) e a apreensão do processo temático subjetivo do adoecimento pelas drogas psicoativas. No lago, são expressas as causas da dependência de drogas, da mesma forma, nas nuvens, as drogas de dependência e, finalmente, a chuva, as consequências da dependência. Assim, o desenho "Metáfora da Chuva" permite com que o autor exponha sua visão de adoecimento pelas drogas e, consequentemente, possa refletir sobre esse processo de adoecimento.

Participaram desta pesquisa 28 mulheres dependentes de drogas que frequentam o CAPS-ad III de uma região administrativa do Distrito Federal. A seleção da amostra da pesquisa foi por conveniência. Como critérios de elegibilidade, adotaram-se, como fatores de inclusão, ser do sexo feminino, com idade acima de dezoito anos, dependente de qualquer substância psicoativa, usuária desse serviço de saúde mental e ter concordado em participar da pesquisa e assinado o Termo de Consentimento Livre e Esclarecido (TCLE). Como critérios de exclusão: não ter capacidade cognitiva ou motora para responder a entrevista ou desenvolver o desenho e não aceitar participar da pesquisa.

A coleta de dados ocorreu no período de agosto de 2017 a junho de 2019, a partir de um único encontro individual com cada paciente, com duração média de uma hora e meia; era iniciado com uma entrevista semiestruturada para coleta de dados sociodemográficos, clínicos e psiquiátricos, posteriormente, as participantes realizaram o desenho "Metáfora da Chuva". Nessa etapa, as mulheres também responderam a um inquérito sobre o desenho realizado. E, finalmente, foram aplicados questionários para verificar depressão e ansiedade. Quanto às entrevistas e questionários, as respostas foram registradas por escrito logo após as sessões e foram analisadas, junto com o desenho realizado, somente após a autorização de cada uma das mulheres participantes. 
Com o Questionário sociodemográfico, clínico e psiquiátrico elaborado pelas pesquisadoras, obtiveram-se as seguintes informações: faixa etária, situação conjugal, número de filhos, grupo étnico, estado de procedência, trabalho, escolaridade, religião, droga de dependência, idade em que teve o primeiro contato com SPA, histórico psiquiátrico, comorbidades, tentativa ou ideação suicida, tempo de tratamento e terapia medicamentosa. Os dados foram descritos em tabelas e foram realizadas análises descritivas simples e calculada a média percentual (porcentagem).

O Inventário de Depressão de Beck (BDI) avaliou a intensidade de sintomas de depressão ${ }^{(7)}$. Consiste de um questionário de 21 questões sobre como o indivíduo se sentiu na última semana, incluindo o dia da entrevista. Já o Inventário de Ansiedade de Beck (BAI) avaliou os sintomas de ansiedade ${ }^{(8)}$. Também é composto por um roteiro com 21 perguntas que refletem sintomas somáticos, afetivos e cognitivos da ansiedade, da última semana e incluindo o dia da entrevista. Os inventários (BDI e BAI) são escalas sintomáticas de rastreamento de depressão (BDI) e de ansiedade (BAI), autoaplicadas, de quatro possibilidades de respostas para cada resposta e que variam de intensidade. Para avaliar a intensidade, contam com um valor de 0 a 3 para cada questão, que se somam ao final, para obter o resultado final em vários níveis ${ }^{(7-8)}$.

Para o BDI, os escores de 0-9 significam que a pessoa não está deprimida, de 10-18 indica que o indivíduo tem depressão leve, de 19-29 denota depressão moderada e já de 30-63 sinaliza depressão severa. Na pontuação do BAI, um escore total de 0-7 designa que a pessoa não tem ansiedade ou tem em grau mínimo; um escore de 8-15 aponta uma ansiedade leve; de 16-25 notifica uma ansiedade moderada e, finalmente, um escore de 25-63 manifesta uma ansiedade severa no indivíduo ${ }^{(8)}$. As respostas do BDI e do BAI foram apresentadas em quadro que expõe a classificação dos sintomas de ansiedade e depressão e também foram desenvolvidas análises descritivas simples e calculada a média percentual (porcentagem).

O desenho "Metáfora da Chuva" foi realizado pelas participantes com os seguintes instrumentos: folha de papel A4 branca, caixa de lápis de cor, giz de cera, canetinhas hidrográficas coloridas, lápis preto e borracha. Após explicação da técnica, foi apresentada a questão norteadora: "Fale-me a respeito da relação com a dependência de drogas": causas, drogas de abuso e consequências da dependência de drogas. Para análise dos desenhos, foram seguidos os passos: (a) observação sistemática dos dados projetados visual e verbalmente pelas mulheres participantes; (b) seleção dos dados por semelhanças temáticas e a aproximação das suas subcategorias; (c) leitura flutuante das unidades temáticas e das suas subcategorias; e (d) análise e interpretação dos dados.

Os dados foram submetidos a análise temática de conteúdo qualitativo, do tipo temático estrutural, que possibilitou a identificação de subcategorias no sentido de único tema, pois a frequência apresentou a significância no conteúdo das análises ${ }^{(9)}$. Consequentemente, a partir das três grandes categorias 
abordadas - as causas da dependência de drogas, os impactos ou as consequências decorrentes do uso abusivo das drogas psicoativas e o enfrentamento em relação à dependência de drogas - convergiram-se outras subcategorias (dimensões). A fim de garantir o anonimato das mulheres entrevistadas na pesquisa, as participantes dependentes de drogas foram identificadas na redação pela letra "M" acompanhada do número correspondente à ordem das entrevistas (de M1 a M28).

No inquérito sobre o desenho, as mulheres expuseram o título do desenho, a continuidade à frase “Toda vez que eu 'chovo', eu me sinto...” com a sugestão de algumas palavras: feliz, triste, confiante, forte, decepcionada, fracassada - a fim de expressar o momento atual - enfrentamento das drogas. Foi disponibilizado tempo para as mulheres falarem sobre seu desenho, caso quisessem. Para a validação do desenho, foi também aplicado um questionário fechado, que continha as perguntas que deveriam ser respondidas com sim ou não: "Você tem dificuldade de falar sobre sua dependência de drogas?", "Você considera que com esta dinâmica ("Metáfora da Chuva") foi mais fácil falar sobre o assunto?", "Você considera que esta dinâmica permitiu que você visualizasse melhor o processo da dependência: causas e consequências?" e "Se você conseguiu visualizar melhor esse processo, considera que isso te deixou mais segura e confiante para continuar o tratamento da dependência de drogas?”. Sobre essas respostas, foram realizadas análise descritiva simples e calculada a média percentual (porcentagem) e apresentadas descritas em gráfico.

Este trabalho é um subprojeto da pesquisa intitulada "A Arteterapia como dispositivo terapêutico nas toxicomanias", que foi aprovado pelo Comitê de Ética em Pesquisa da Fundação de Ensino e Pesquisa (CEP/FEPECS), sob o CAAE $n^{\circ}$ 44625915400005553. As participantes do estudo foram consultadas quanto ao desejo de participarem do estudo e, após aceitarem, assinaram o TCLE. Foram assegurados a elas o sigilo, a confiabilidade, a privacidade, a proteção da imagem e a garantia de que as informações obtidas com a pesquisa fossem verdadeiras e fossem utilizadas nas esferas científicas ou acadêmicas.

\section{RESULTADOS E DISCUSSÃO}

A faixa etária das participantes variou de 26 a 64 anos e, do total de participantes $(n=28)$, prevaleceu a idade entre 36-50 anos em quinze participantes (53,6\%), obteve-se uma média de 45,6 anos. O grau de escolaridade variou de Ensino Fundamental incompleto a Ensino Superior completo e evidenciou-se que maioria tinha baixa escolaridade: dezessete $(60,7 \%)$ das entrevistadas não chegaram a cursar o Ensino Médio. Identificou-se que vinte e uma (75\%) das participantes eram solteiras, separadas ou viúvas. Apenas uma das mulheres não tinha filho/a e, entre as demais, dezenove $(70,37 \%)$ tinham até dois filhos/as. O grupo étnico autoreferido que prevaleceu foi de pardas ou negras, com 24 mulheres $(85,7 \%)$. Vinte e uma $(75 \%)$ mulheres alegaram ter alguma religião e, aproximadamente, metade dessas 
relataram ser praticantes. Vinte e quatro $(85,7 \%)$ mulheres residiam no Distrito Federal e as demais, em regiões do Entorno. Vinte e cinco (89\%) participantes não estavam desenvolvendo atividade laboral fixa no momento.

A média de idade (45,6 anos) encontrada nesta pesquisa assemelha-se com outro estudo ${ }^{(10)}$. realizado com mulheres, no qual a amostra foi predominantemente adulta, com média de idade de 41,4 anos. A faixa etária predominante no estudo corrobora com outros estudos ${ }^{(11)}$ que abordaram o perfil sociodemografico de usuários de CAPS-ad em outros estados brasileiros. Em geral, as mulheres dependentes de substâncias psicoativas iniciam o consumo e têm problemas com as drogas em idade mais avançada do que os homens ${ }^{(1)}$.

A baixa escolaridade evidenciada no estudo corrobora com resultados encontrados em pesquisas realizadas no Brasil $^{(10,12-13)}$. Em estudo realizado ${ }^{(12)}$ com homens dependentes de drogas, os autores puderam constatar que 65,5\% dos usuários cursaram até o Ensino Fundamental. Com isso, é possível evidenciar a semelhança do nível de escolaridade em ambos os sexos.

Em relação à situação conjugal, 75\% das participantes relataram estarem solteiras, divorciadas ou viúvas, dado que se assemelha ao estudo realizado por Mastroianni, Macris, Gomes, Camargo (2016), realizado no interior do estado de São Paulo, que evidencia a prevalência de indivíduos solteiros (61,5\%). Em outros estudos ${ }^{(13)}$, também preponderaram os relatos de ausência de companheiro(a)/ relacionamento estável. Em contrapartida, vinte e sete $(96,4 \%)$ usuárias possuem filho. Em outra pesquisa ${ }^{(12)}$, o percentual de indivíduos com filho é de $61 \%$ a $68 \%$, relativamente menor do que o encontrado nesta pesquisa $(96,4 \%)$.

Em relação à atividade laboral, o elevado percentual de desempregados corrobora estudos ${ }^{(12-13)}$ realizados em CAPS-ad da Região Metropolitana de Curitiba - PR e Jaci - SP, que evidenciaram a maioria dos usuários em situação de desemprego. Quanto à religião, um estudo ${ }^{(14)}$ sobre qualidade de vida e religião de dependentes químicos em recuperação, apontou que 93,9\% relataram ter alguma religião, pouco mais que o percentual encontrado na pesquisa, e 57,2\% dizem ser praticantes, que se assemelha ao resultado. A religiosidade pode funcionar como fator de proteção para os indivíduos dependentes de álcool e outras drogas. No estudo de Silva, Guimarães e Salles ${ }^{(15)}$, a religiosidade foi apontada como principal mecanismo de prevenção de recaída, devido ao auxílio na promoção da fé e apoio para lidar com mudanças, dor e sofrimento.

Quanto às situações clínica e psiquiátrica, quatorze (50\%) mulheres eram alcoolistas, doze $(42,8 \%)$ delas relataram ter iniciado o uso de drogas na adolescência, entre 15 e 19 anos, e nove $(32,1 \%)$ relataram ter iniciado após os 20 anos de idade. Verificou-se que dezessete $(60,7 \%)$ mulheres participantes da pesquisa haviam buscado tratamento anterior em unidade de CAPS-ad, vinte e três 
$(82,1 \%)$ delas tinham confirmação dignóstica de depressão e treze $(46,4 \%)$ tinham de ansiedade como comorbidades psiquiátricas; dezenove $(67,9 \%)$ relataram ideação ou tentativa de suicídio. Constatou-se que todas as mulheres faziam uso de dois ou mais psicofármacos: vinte e cinco $(89,3 \%)$ delas faziam uso de reguladores de humor, vinte e três $(82,1 \%)$ de antidepressivos, seguida de vinte $(71,4 \%)$ de ansiolíticos/hipnóticos entre outros. Treze $(46,4 \%)$ mulheres participantes tinham menos de um ano de tempo de proposta terapêutica no CAPS-ad III.

A pesquisa mostra que $50 \%$ das mulheres eram alcoolistas. Para Macagnan, Menetrier e Bortoloti $^{(16)}$, o relacionamento estável pode ser um fator de proteção na fase adulta, o que pode tornar o individuo que não o possui mais vulnerável ao consumo de substâncias psicoativas, principalmento o álcool. Em relação ao primeiro contato com a droga na adolescência, os resultados contrariam que mulheres dependentes de álcool iniciam o consumo com idade mais avançada ${ }^{(1)}$.

Evidenciou-se que vinte e sete $(96,43 \%)$ das mulheres incluídas neste estudo apresentavam sintomas positivos para ansiedade, enquanto vinte e quatro $(85,71 \%)$ para depressão. Quatorze $(50 \%)$ das mulheres apresentaram depressão severa e treze delas $(46,43 \%)$ ansiedade grave. No Inventário de BDI, os aspectos que mais tiveram pontuação positiva foram: "acha que está sendo punida" e "tem ideia de se matar" - aspectos cognitivo-emocional, “desinteresse nas outras pessoas" - aspecto sensação de perda, "perda do apetite" - aspecto comportamental-somático. Já no Inventário de BAI, os sintomas que obtiveram maior pontuação foram: "atordoada ou tonta", "palpitação ou aceleração do coração", "aterrorizada", "sensação de sufocação" e "medo de perder o controle, como uma combinação de tensão, nervosismo, taquicardia, cefaleia, culpa, choro, insônia, tristeza", “preocupação excessiva”. Aspectos esses que caracterizam a ansiedade e depressão entre as pessoas.

O uso problemático de substâncias psicoativas pode aumentar o risco de desenvolvimento de transtornos mentais ou agravá-los ${ }^{(1)}$. Pereira ${ }^{(17)}$ mostra que há associações entre dependência de álcool e transtornos mentais e psiquiátricos decorrentes do uso da droga. Entre desses transtornos estão a depressão, a ansiedade, a esquizofrenia e outros. Segundo o II Levantamento Nacional de Álcool e Drogas $^{(18)}, 18,5 \%$ dos adultos entrevistados declararam ter sofrido de ansiedade nos últimos doze meses e $23,9 \%$ ter sofrido alguma vez na vida. Quanto à depressão, 15,1\% declararam ter sofrido alguma vez na vida e 9,4\% nos últimos doze meses antes da sessão. Em relação aos homens, as mulheres com dependência de drogas são mais propensas às comorbidades psiquiátricas, principalmente depressão e ansiedade $^{(1)}$.

Mesmo em uso de dois ou mais psicofármacos, entre eles, reguladores de humor, antidepressivos e ansiolíticos/hipnóticos, grande número de mulheres dependentes de drogas pesquisadas ainda apresentavam sintomas, no momento, de depressão e ansiedade graves. Complementam os achados de 
outro estudo, que identificou nos usuários de drogas que não tinham emprego, níveis mais altos de sintomas de depressão, ansiedade e estresse do que no outro grupo empregado ${ }^{(19)}$, como o caso desta pesquisa.

Quanto ao desenho da "Metáfora da Chuva", nenhuma das mulheres participantes apresentou resistência ao desenvolvimento do procedimento. Após o término do procedimento, as mulheres verbalizaram sobre ele, contaram suas histórias de vida atrelada ao seu processo de adoecimento pelas drogas. Os dados foram agrupados em três grandes categorias, a saber: as causas da dependência de drogas, os impactos ou as consequências decorrentes do uso abusivo das drogas psicoativas e o enfrentamento em relação à dependência de drogas.

Dentro de cada grande categoria temática emergiram as respectivas dimensões, organizadas de acordo com a aproximação do tema e do objetivo proposto, por meio as palavras ou frases das respostas mais significativas. Elencaram-se as principais dimensões pertinentes às grandes categorias, segundo a ótica das depoentes, como nos discursos a seguir. Algumas falas ou frases pertenceram a mais de uma dimensão.

\subsection{AS CAUSAS DA DEPENDÊNCIA DE DROGAS}

Nesta categoria, foram desbobradas seis dimensões (problemas): psicológicas ou de comportamento; no relacionamento com a família; socioculturais; relacionadas à violência; biológicas ou físicas e no trabalho, em um total de 86 respostas. No Quadro 1 são expostas as respostas referentes às causas da dependência de drogas.

Quadro 1 - Registro da categoria as causas da dependência de drogas, suas dimensões e respectivas palavras ou frases segundo as mulheres depoentes. Brasília, DF, Brasil, 2020. (n=28);

\begin{tabular}{|c|c|c|}
\hline $\mathbf{N}^{\mathbf{0}}$ & Dimensão & Discursos (palavras e frases) \\
\hline 1 & $\begin{array}{c}\text { Problemas psicológicos ou } \\
\text { de comportamento }=31 \\
\text { respostas }\end{array}$ & 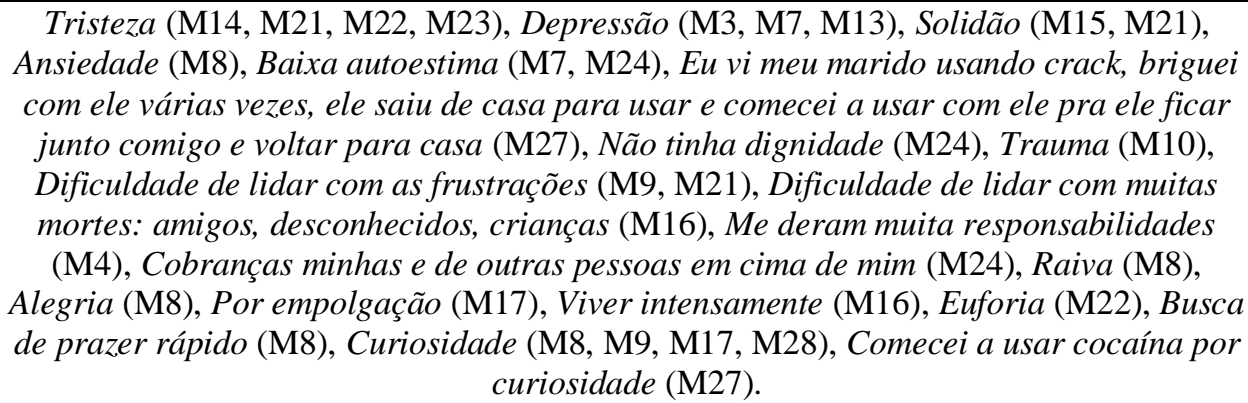 \\
\hline 2 & $\begin{array}{c}\text { Problemas no } \\
\text { relacionamento com a } \\
\text { família }=26 \text { respostas }\end{array}$ & $\begin{array}{l}\text { Morte na família (M16, M19), Perda de ente querido (M3), Perdas de mãe e pai (M6), } \\
\text { Mortes dos pais (M7), Separação (M6, M7, M15), O que me motivou a usar o crack foi } \\
\text { minha separação com meu marido (M25), Perda da família (M23), Perda dos filhos } \\
\text { (M24), Separação dos filhos (M15), Perda de filho: foi trocado na maternidade (M16), } \\
\text { Mãe bebia (M11), O marido bebia (M18), Eu vi meu marido usando crack, briguei com } \\
\text { ele várias vezes, ele saiu de casa para usar e comecei a usar com ele pra ele ficar junto } \\
\text { comigo e voltar para casa (M27), Influência de primos que usavam drogas (M11), }\end{array}$ \\
\hline
\end{tabular}




\begin{tabular}{|c|c|c|}
\hline & & $\begin{array}{c}\text { Problemas no casamento e com os filhos (M15), Casa tristeza (M21), Falta de apoio } \\
\text { familiar (M14, M21), Decepções em casa (M21), Decepção no meu lar (M22), Brigas } \\
\text { famíliares (M13, M23), Pela violência dentro de casa com minha mãe e meus maridos } \\
\text { etc (M24). }\end{array}$ \\
\hline 3 & $\begin{array}{l}\text { Problemas socioculturais }= \\
21 \text { respostas }\end{array}$ & $\begin{array}{c}\text { Pessoas oferecendo (M1), Me deram (M12), Eu morava na rua e me obrigaram a usar } \\
\text { (M24), Morar sozinha (M15), Conceitos sociais (M11), Porque podia (M20), Influência } \\
\text { das amizades (M16), Más amizades (M5), Influência de pessoas que já usavam (M5), } \\
\text { Amizades (M11, M14), Influência de amigos (M21, M28), Com amigos de bar (M22), } \\
\text { Meus amigos falaram que era bom e usei cocaína por } 10 \text { anos (M27), Perda de amigos } \\
\text { (M23), Meus amigos se afastaram de mim (M24), Farra (M2), Comemoraçôes (M8), } \\
\text { Passar o tempo (M8), No clube (M21). }\end{array}$ \\
\hline 4 & $\begin{array}{l}\text { Problemas relacionados com } \\
\text { a violência }=3 \text { respostas }\end{array}$ & $\begin{array}{l}\text { Brigas famíliares (M13, M23), Pela violência dentro de casa com minha mãe e meus } \\
\text { maridos etc (M24). }\end{array}$ \\
\hline 5 & $\begin{array}{l}\text { Problemas biológicos ou } \\
\text { físicos }=3 \text { respostas }\end{array}$ & Insônia (M6, M7), Mãe bebia (M11). \\
\hline 6 & $\begin{array}{l}\text { Problemas no trabalho }=2 \\
\text { respostas }\end{array}$ & Perda de emprego (M7), Falta de emprego (M23). \\
\hline
\end{tabular}

Fonte: Dados do estudo

No que diz respeito a essas categorias de causas da dependência de drogas pelas mulheres participantes, pode-se perceber, por meio das falas mencionadas no Quadro 1, que os problemas de ordem psicológicos ou de comportamento representaram o maior número de respostas (31), seguido de problemas no relacionamento com a família (26 respostas), problemas socioculturais (21 respostas). Já os problemas biológicos ou físicos, relacionads à violência e ao trabalho apresentam um quantitativo de respostas menor do que as demais respostas (3, 3 e 2 respostas, respectivamente).

Apreende-se que os sintomas de depressão, de tristeza ou de solidão, a inabilidade de resolver problemas ou dificuldades em lidar com as frustrações, separações ou dissolução da família, estrutura familiar precária, conflituosa e estressante e problemas no relacionamento social foram os aspectos mais citados pelas mulheres como fatores que as levaram para a dependência de drogas. Pontos estes que culminam com uma vida cotidiana permeada por inúmeras vulneravilidades emocionais, familiares e sociais. Outro aspecto relevante é que a violência foi citada somente no âmbito doméstico. Para tanto, os problemas biológicos ou físicos, relacionado à violência ou no trabalho foram pouco citados entre as mulheres.

\subsection{OS IMPACTOS OU AS CONSEQUENNCIAS DECORRENTES DO USO ABUSIVO DAS DROGAS PSICOATIVAS}

Entre as falas das mulheres participantes sobre as consequências ou os impactos que provocaram o uso abusivo de drogas psicoativas, elencaram-se oito dimensões (problemas): psíquicos ou comportamentais; no relacionamento com a família; no trabalho ou no aspecto econômico-financeiro; 
relacionados com a violência; na saúde física; socioculturais; com a educação ou nenhum problema - em um total de 112 respostas. No Quadro 2 são evidenciadas as respostas referentes os impactos ou as consequências decorrentes do uso abusivo das drogas psicoativas.

Quadro 2 - Registro da categoria os impactos ou as consequências decorrentes do uso abusivo das drogas psicoativas, suas dimensões e respectivas palavras ou frases conforme as mulheres participantes. Brasília, DF, Brasil, 2020. (n=28);

\begin{tabular}{|c|c|c|}
\hline $\mathbf{N}^{\mathbf{0}}$ & Dimensão & Discursos (palavras e frases) \\
\hline 1 & $\begin{array}{l}\text { Problemas psíquicos ou } \\
\text { comportamentais }=48 \\
\quad \text { respostas }\end{array}$ & $\begin{array}{c}\text { Depressão (M2, M3, M6, M7, M8, M14, M18, P21, P23, M24, M26), Tristeza (M8, } \\
\text { M10, P21, P22, M27), Choro (M4, M27), Não tenho vontade de arrumar a casa ou } \\
\text { cuidar de mim (M27), Dor - angústia (M17), Angústia (M8), Arrependimento (M8, } \\
\text { P22), Vergonha (M8), Decepção (M21), Desespero (M4), Mágoa (M4), Solidão (M6, } \\
\text { M10, M21, M24, M25), Isolamento social (M28), Tentativa de suicídio (M6), Tenho } \\
\text { vontade às vezes de morrer, me suicidar, chorar (M27), Perdi minha autoestima (M5), } \\
\text { Raiva (M8), Perda de caráter - confiança (M15), Perda do respeito e confiança (M23), } \\
\text { Perda da dignidade (M15), Não confio em mim e as pessoas também (M20), Ansiedade } \\
\text { (M18), Sintomas psicóticos (M9), Alucinação (M24), Vejo visóes de medo (M27), } \\
\text { Paranoia (M20), Síndrome do pânico - agorafobia (M20), Compulsão alimentar, eu } \\
\text { provoco o vômito }(\mathrm{M} 26) .\end{array}$ \\
\hline 2 & $\begin{array}{l}\text { Problemas no } \\
\text { relacionamento com a } \\
\text { família }=21 \text { respostas }\end{array}$ & $\begin{array}{l}\text { Separação do marido (M1) Separação conjugal (M6), Perdi meu marido (M25), Perdas } \\
\text { de pessoas da família (M10), Perdi pessoas da família que me amavam (M27), Perdi } \\
\text { meus filhos (M23, M24), Meus filhos se afastaram de mim (M25), Magoou pessoas da } \\
\text { família (M8), As maiores feridas em meus filhos que não curam (M20), Os filhos me } \\
\text { jogam na cara as consequências (M20), Abandonei minha casa (M25), Afastamento da } \\
\text { família (M20), Perdi a confiança da minha família (M5), Sofrimento familiar (M6), } \\
\text { Violência doméstica (M23), Brigas domésticas (M27), Brigas familiares (M6, M19), } \\
\text { Conflitos familiares (M10), Conflito familiar com a filha (M11). }\end{array}$ \\
\hline 3 & $\begin{array}{l}\text { Problemas no trabalho ou no } \\
\text { aspecto econômico- } \\
\text { financeiro }=13 \text { respostas }\end{array}$ & $\begin{array}{c}\text { Desemprego (M6), Perda do emprego (M15, M23), Perda do serviço (M19), Perdi meu } \\
\text { emprego (M23, M24), Perdi trabalho (M27), Perda financeira (M3), Perda de dinheiro } \\
\text { (M28), Falta de dinheiro (M8), Só destruição, miséria (M13), Perdi tudo, virei uma } \\
\text { mendiga sem nada (M24), Perdi de tudo dentro de casa (M23). }\end{array}$ \\
\hline 4 & $\begin{array}{l}\text { Problemas relacionados com } \\
\text { a violência }=10 \text { respostas }\end{array}$ & $\begin{array}{c}\text { Assédio masculino (M11), Abusada sexualmente (M16), Me bateram na rua (M27), } \\
\text { Agressão física (M6), Agressividade (M11), Violência física (M6), Violência doméstica } \\
\text { (M23), Brigas domésticas (M27), Brigas familiares (M6, M19). }\end{array}$ \\
\hline 5 & $\begin{array}{l}\text { Prejuízo no funcionamento } \\
\text { físico ou problemas de } \\
\text { saúde/físicas }=9 \text { respostas }\end{array}$ & $\begin{array}{c}\text { Perda de peso (M28) Fiquei muito magra (M5), Tive várias overdoses (M27), Ressaca } \\
\text { (M8), Gastrite (M14, M26), Hipertensão arterial (M1, M14), Perdi noites de sono } \\
\text { (M27). }\end{array}$ \\
\hline 6 & $\begin{array}{l}\text { Problemas socioculturais }= \\
8 \text { respostas }\end{array}$ & $\begin{array}{l}\text { Perdi meus amigos (M5), Falsas amizades (M11), Mortes (M16), Fui morar na rua } \\
\text { (M16), Preconceito (M4), Difamação (M11), Fofoca (M11), Isolamentos (M10). }\end{array}$ \\
\hline 7 & $\begin{array}{l}\text { Problemas com a educação } \\
\quad=2 \text { respostas }\end{array}$ & Perdeu conhecimento (M16), Parei de estudar (M19). \\
\hline 8 & $\begin{array}{c}\text { Nenhum problema }=1 \\
\text { resposta }\end{array}$ & Não perdi nada (M12) \\
\hline
\end{tabular}

Fonte: Dados da pesquisa

Refletindo sobre as categorias de consequências da dependência de drogas pelas mulheres participantes, pode-se depreender, por meio das falas ou frases mencionadas no Quadro 2, que os 
problemas de ordem psíquica ou de comportamento representam o maior número de respostas (48), seguidos de problemas no relacionamento com a família ( 21 respostas), problemas no trabalho ou no aspecto financeiro (13 respostas), problemas relacionados com a violência (10 respostas), prejuízo no funcionamento físico ou problemas de saúde/físicas (9 respostas), socioculturais (8 respostas). Já os problemas com educação ou nenhum problema obtiveram um número reduzido de respostas $(2$ e 1 respostas, respectivamente).

As falas apresentadas refletem a grandiosidade do impacto da dependência de drogas sobre a vida das mulheres em vários aspectos de vida, desde o contexto pessoal, físico e psiquiátrico, como nas outras dimensões familiares, financeira, social, educacional. Nessa perspectiva, a mulher dependente de drogas se torna altamente vulnerável a situações de risco iminente.

Apreende-se que o cotidiano dessas mulheres era permeado por uma vida bastante vulnerável, evidenciada pelas características apontadas pelas mulheres em relação aos seus aspectos emocionais, familiares ou sociais. Nesse tocante, sugere-se que esse esforço das mulheres em conciliar suas emoções e sentimentos negativos, desestrutura das relações familiares e o ambiente violento caracterizou a busca pela obtenção de prazer imediato e do alívio das dores emocionais pelo uso desenfreado de substâncias psicoativas. Assim, fica evidenciado que se a proposta inicial de lidar ou acabar com as dores e sofrimentos mencionados como causa do uso de drogas, agravou-se muito mais nas consequências da dependência de drogas. Aspecto relevante na dependência de drogas, pois o agravamento das condições de vulnerabilidade e, ainda, o agregar de novos componentes negativos, tornando os problemas e a vulnerabilidade mais profícuos, como os demonstrados pelas falas vinculadas em relação às consequências do uso de drogas pelas mulheres.

Um consolidado sobre as principais diferenças entre causas e impactos ou consequências decorrentes do uso abusivo das drogas psicoativas, de acordo com as perspectivas das mulheres dependentes de drogas participantes da pesquisa, são descritas a seguir. Sobre as categorias encontradas, de seis dimensões (problemas) encontradas como causa da dependência e 86 respostas se desbobraram para oito e 112 respostas nas consequências. Dessa maneira, com o uso abusivo de drogas, as consequências e vulnerabilidades aumentaram negativamente em termos quantitativos e qualitativos nas mulheres participantes da pesquisa.

Por exemplo, nos aspectos psiquiátricos, as mulheres relataram surtos psicóticos, transtornos depressivos, do pânico e alimentar, risco de suicídio; diagnósticos psiquiátricos associados e após a dependência de drogas psicoativas podem favorecer ao agravamento dos problemas emocionais graves e das habilidades em resolver os problemas. Evocam, assim, o humor depressivo, ansioso e hostil e geram fortes sentimentos de culpa ou de baixa autoestima e arrependimento e de retraimento social. As mulheres 
apresentam mais comorbidades psiquiátricas - como depressão e ansiedade - e tentativas de suicídio do que os homens e os fatores ambientais têm maior influência sobre elas do que os fatores genéticos ${ }^{(1)}$.

Nos aspectos físicos, ao desenvolverem problemas gastrintestinais, cardíacos, insônia e na aparência física, a resistência pode baixar e predispor as mulheres a desenvolverem inúmeras infecções. Em uma pesquisa sobre os motivos atribuídos por usuários à procura de tratamento em um CAPS-ad foi possível incluir agravos na saúde e nos relacionamentos sociais, além do desejo de reconstruir suas relações familiares e a reinserção social ${ }^{(20)}$.

Ademais, a dependência de drogas psicoativas agrava os problemas no relacionamento com a família e com os parceiros, desestrutura ainda mais a dinâmica e a estrutura familiar, marcada por separações, por violência, negligência com filhos e afazeres domésticos e pela fuga de casa, aspectos que se tornam persistentes ou recorrentes causados ou agravados pelos efeitos da intoxicação ou abuso das drogas. Pesquisa qualitativa, ao analisar a dinâmica familiar de mulheres-mães, antes, durante e após o convívio com as drogas constatou que a dependência de substâncias psicoativas tem interferido diretamente as relações familiares, aflige os laços criados, no amparo e na relação segura, adquirida ao longo da convivência familiar. No período anterior às drogas, as relações familiares foram consideradas como boas, em oposição ás do contexto das drogas, na qual se evidenciaram a naturalização da vida na rua, o roubo, a prostituição como formas de sustentar a dependência da droga e a rejeição familiar quando houve a possibilidade de reaproximação familiar ${ }^{(21)}$.

Outro aspecto relacionado com os laços familiares foi o estudo de Pereira, Andrade, Espínola, Azevedo, Nogueira, Ferreira Filha ${ }^{(22)}$,que evidenciou que, entre os adolescentes que conviviam com pais alcoolistas e mães com maior nível de escolaridade, tiveram chance reduzida de manifestarem adoecimento psíquico; já entre os adolescentes que não conviviam com familiares alcoolistas, a maior chance para desenvolverem o agravo esteve vinculada ao nível de escolaridade paterna, ser do sexo feminino e não pertencer à família nuclear. $\mathrm{O}$ impacto das drogas sobre a vida funcional das mulheres ainda se alargou trazendo repercussões sobre o aspecto econômico-financeiro, após, especialmente, as inúmeras perdas e dificuldade de vínculo empregatício. Os achados de autores ${ }^{(23)}$ apontam como aspecto relevante à alta percentagem de mulheres que abandonaram o exercício de papéis ocupacionais em decorrência da dependência de drogas.

No tocante aos problemas relacionados com a violência, além do agravamento da violência doméstica, surgiram, como consequência do uso abusivo de substâncias, a violência externa física e sexual. Dados que corroboram com a pesquisa que aduz que a violência, em especial na infância, é um precursor para o consumo abusivo de drogas, porque vulnerabiliza as mulheres, além de a dependência de drogas desencadear a reincidência de abusos físicos, sexuais e psicológicos ${ }^{(24)}$. Outro estudo de revisão 
integrativa da literatura evidenciou, cientificamente, que a dependência química é fator de risco para as violências física, psicológica e sexual no universo feminino, pois favorece repercussões negativas e significativas para a saúde física e mental da vítima, o que torna emergente a implementação de medidas efetivas que contribuam para a redução dessa problemática e a minimização dessas consequências ${ }^{(25)}$.

No padrão sociocultural, as consequências da dependência continuaram a refletir-se sobre os problemas nos relacionamentos com amizades (houve relato da pessoa ter ficado em situação de rua) aliados aos preconceitos sociais sofridos pelas mulheres após a dependência de drogas instalada. O conhecimento do contexto social de mulheres dependentes de crack evidencia um universo complexo de significados, que descortina ideias pré-concebidas, realidades sofridas, permeadas por violência, desestrutura familiar. A a mudança só vai ser transformadora, se forem executadas ações em saúde mental pautadas nas demandas das mulheres dependentes de drogas, no caso o crack, e possibilitando um cuidado voltado para o aspecto social, transformador de realidades ${ }^{(26)}$. Sobre o relacionamento com amizades, Dagnoni e Garci ${ }^{(27)}$ acrescentam que as pessoas dependentes de substâncias psicoativas, frequentemente, relatam influência direta e indireta de amigos no início e na manutenção do uso de drogas e a dependência reduz o número de amigos, até restringi-los ao ambiente somente familiar.

Também surgiram os problemas com a educação, que refletiram na baixa escolaridade e, consequentemente, na dificuldade de arrumar um emprego de melhor qualificação e salário, o que favorece as dificuldades financeiras ou a privação econômica. Dessa forma, no processo de enfrentamento ineficaz pelo abuso das drogas, agregam-se os processos de pensamento e sensorial perturbados, risco de violência direcionada a si mesmas e de suicídio, a baixa autoestima se torna crônica, os processos familiares disfuncionais e a interação social se agravam, acrescenta-se a tensão do papel do cuidador, déficit no autocuidado, nutrição desequilibrada, manutenção ineficaz da saúde e maior risco de infecção, além do padrão de sono perturbado e o acúmulo de outros transtornos psiquiátricos.

Segundo estudo, o crack, por exemplo, é representado como um elemento devastador e desagregador, responsável por causar abandono ou afastamento das funções femininas, além do que, a figura da mulher dependente de substâncias é vista como um distúrbio moral, o que acarreta uma representação depreciativa e dificulta a procura por tratamento e a recuperação das usuárias ${ }^{(28)}$. Situação diferente foi encontrada na fala de (M12), quando diz que "Não perdi nada", o que pode inferir que ela teve dificuldade de fazer a reflexão do seu processo de adoecimento, provavelmente por estar em um estágio de pré-comtemplação, em vez de não ter tido realmente sequela da dependência de drogas. Notase que o estágio de pré-contemplação considerado o primeiro estágio de mudança, desenvolvido por Prochaska, DiClemente e Norcross ${ }^{(29)}$, é quando a pessoa não considera que o abuso de drogas lhe traga 
algum problema, assim, a pessoa não tem nenhuma preocupação, não sabe ou não aceita que o abuso de substâncias seja um risco nocivo ou que possa lhe trazer malefísios para a pessoa.

Estudo qualitativo, que objetivou conhecer a percepção de mulheres em situação de dependência química no interior de Mato Grosso, revelou que as mulheres em tratamento possuiam experiências semelhantes ligadas às drogas, mas tendem a responder de forma distinta ao tratamento, e concluiu que as comunidades terapêuticas devem empenhar-se no reconhecimento das fragilidades apresentadas pelas mulheres desde o acolhimento, para que sejam elaborados planos terapêuticos pautados nas potencialidades, nas necessidades dessas mulheres, para que, ao supri-las possam ser viabilizadas maiores possibilidades de recuperação ${ }^{(30)}$.

\subsection{O ENFRENTAMENTO EM RELAÇÃO À DEPENDÊNCIA DE DROGAS}

$\mathrm{Na}$ terceira categoria advinda a partir da frase: "Toda vez que eu chovo eu me sinto..." emergiram duas subcategorias: uma negativa e outra positiva são demosntradas no Quadro 3.

Quadro 3 - Registro das subcategorias surgidas na temática do enfrentamento da dependência de drogas pelas as mulheres participantes da pesquisa surgidas a partir da frase: "Toda vez que eu 'chovo' eu me sinto...”. Brasília, DF, Brasil, 2020. $(\mathrm{n}=28)$;

\begin{tabular}{|c|c|c|}
\hline $\mathbf{N}^{\mathbf{0}}$ & Categoria Negativa & Categoria Positiva \\
\hline 1 & Triste (M2, M9, M13, M19, M22, M25, M26, M27, & Confiante (M1, M2, M3, M12, M15) = 5 respostas \\
\hline 2 & $\begin{array}{c}\text { Fracassada }(\mathrm{M} 2, \mathrm{M} 7, \mathrm{M} 10, \mathrm{M} 11, \mathrm{M} 18, \mathrm{M} 27, \mathrm{M} 28)=7 \\
\text { respostas }\end{array}$ & Feliz (M1, M2, M6, M16) = 4 respostas \\
\hline 3 & $\begin{array}{c}\text { Decepcionada }(\mathrm{M} 2, \mathrm{M} 14, \mathrm{M} 21, \mathrm{M} 22, \mathrm{M} 23, \mathrm{M} 24)=6 \\
\text { respostas }\end{array}$ & Forte (M1, M2, M5) = 3 respostas \\
\hline 4 & Magoada $(\mathrm{M} 4)=1$ resposta & Em evolução (M3) =1 resposta \\
\hline 5 & Com medo de não conseguir proseguir $(\mathrm{M} 8)=1$ resposta & - \\
\hline 6 & Com dor $(\mathrm{M} 17)=1$ resposta & - \\
\hline 7 & Sufocada $(\mathrm{M} 19)=1$ resposta & - \\
\hline 8 & Que a caminhada é longa $(\mathrm{M} 20)=1$ resposta & - \\
\hline & Solitária $(\mathrm{M} 21)=1$ resposta & \\
\hline Total & 28 & \\
\hline
\end{tabular}

Fonte: Dados do estudo

A partir das palavras do Quadro 3, observa-se que as entrevistadas, ao visualizarem o desenho e imaginarem-se diante do ciclo representado pela "Metáfora da Chuva", optaram mais pelo uso das palavras classificadas na categoria negativa, com destaque em triste, decepcionada e fracassada, para representar os seus sentimentos em relação à dependência de drogas, com um total de 28 respostas. No entanto, ao mesmo tempo, houve o aparecimento de palavras positivas, em destaque para as palavras confiante, feliz e forte, com total de 13 respostas. 
Pode-se depreender que, ao refletirem sobre seu processo de adoecimento, as mulheres expuseram mais os sentimentos negativos pela própria dificuldade delas em lidar ou manejar com a sua dependência de drogas, naquele momento de vida, tendo em vista que a maioria das mulheres participantes tinha pouco tempo de proposta terapêutica ao CAPS-ad III. A ambivalência é característica da fase de contemplação, dentro dos estágios de mudança definidos por Prochaska, DiClemente e Norcross ${ }^{(29)}$, quando a pessoa considera perceber tanto os aspectos negativos como positivos em relação ao seu abuso de substâncias.

Um estudo sobre a representação social na perspectiva de dependentes de drogas constatou que o dependente está sempre ligado a uma concepção negativa, de um sujeito não confiável e mau-caráter, ele é visto como um doente que não tem capacidade de lutar contra sua dependência. Esses aspectos ganham veracidade interna e conduzem o sujeito de acordo com as formas pelas quais compreendem sua realidade ${ }^{(31)}$.

Uma pesquisa qualitativa realizada com vinte dependentes de drogas em tratamento em um CAPS-ad identificou determinantes intra e interpessoais na recaída, percebidos pelos dependentes de substâncias psicoativas. Entre determinantes intrapessoais expressos foram: como a autoeficácia expressa pela autoconfiança em interromper o consumo de drogas; a expectativa de resultado pela antecipação dos efeitos prazerosos da droga; a motivação pela ausência de volição em interromper o consumo; o enfrentamento pela dificuldade de confrontar os problemas diários; os estados emocionais negativos e positivos; e a fissura. Já entre os determinantes interpessoais citados foram o apoio social relacionaram-se a influência de terceiros ${ }^{(32)}$. Esses aspectos reforçam os achados deste estudo.

Complementam os achados de Guerra e Vandenberghe ${ }^{(33)}$, ao desenvolverem uma revisão bibliográfica integrativa para conhecer a produção científica nacional a respeito da reabilitação do usuário e concluíram que há uma proliferação de estratégias e programas na literatura, entretanto a sua eficácia está em abordar o sujeito por inteiro e adaptar-se às necessidades individuais como guia condutor do tratamento.

$\mathrm{Na}$ tentativa de melhor visualização das imagens elaboradas pelas mulheres participantes, foram selecionados dois desenhos representando a "Metáfora da Chuva" para melhor exemplificar este estudo. As imagens foram expostas junto com o título, respostas e dados das autoras e apresentados ao lado dos desenhos, no Quadro 4. 
Quadro 4 - Desenhos “Metáfora da Chuva” de M5 e M8. Brasília, DF, Brasil, 2020.

\begin{tabular}{|c|c|}
\hline 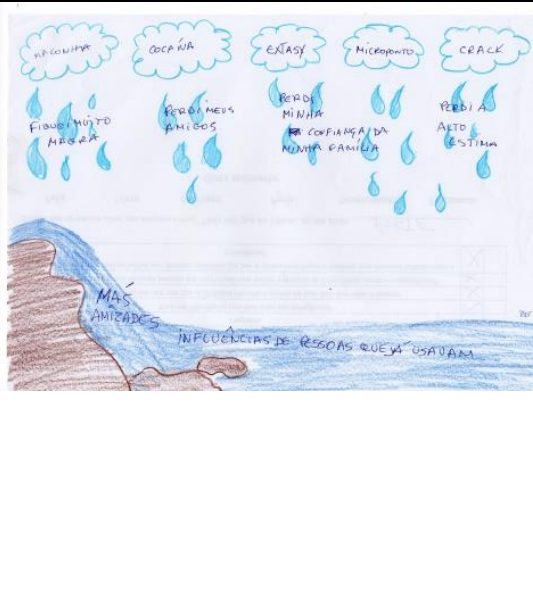 & $\begin{array}{l}\text { Mundo das drogas } \\
\text { Causas: Más amizades. Influência de pessoas que já usavam. Consequências: Perdi } \\
\text { minha autoestima. Fiquei muito magra. Perdi a confiança da minha família. Perdi } \\
\text { meus amigos. Toda vez que eu chovo, eu me sinto forte. } \\
\text { Autoria: M5, } 36 \text { anos, parda, dependente de álcool e crack e tinha diagnóstico de } \\
\text { Transtorno Afetivo Bipolar, em proposta terapêutica no CAPS-ad há } 14 \text { dias, natural } \\
\text { de Brasília, divorciada, mãe de dois filhos, Ensino Fundamental completo, sem } \\
\text { religião, estava desempregada no momento e vivia sozinha com renda do ex- } \\
\text { companheiro, mas naquele momento estava em situação de rua pelo uso de abusivo } \\
\text { de drogas. Iniciou o uso de substâncias psicoativas aos } 19 \text { anos, tem histórico de } \\
\text { internação desde } 2012 \text { e de overdose por cocaína e pancreatite pelo uso abusivo de } \\
\text { álcool. Ideação suicida, uma vez, e refere já ter sofrido violência verbal e física. Faz } \\
\text { uso de dois tipos de antidepressivos, três ansiolíticos, antipsicóticos, } \\
\text { anticonvulsivante e estabilizador de humor. } \\
\text { Sintomas de depressão (BDI) severa e ansiedade (BAI) moderada. }\end{array}$ \\
\hline & $\begin{array}{l}\text { A vida sem álcool } \\
\text { Causas: Ansiedade. Raiva. Alegria. Busca de prazer rápido. Curiosidade. } \\
\text { Comemorações. Passar o tempo. Consequências: Depressão. Tristeza. Angústia. } \\
\text { Arrependimento. Vergonha. Raiva. Magoou pessoas da família. Falta de dinheiro. } \\
\text { Ressaca. Toda vez que eu chovo, eu me sinto com medo de não conseguir proseguir. } \\
\text { Autoria: M8, } 41 \text { anos, branca, alcoolista e tem como comorbidade psiquiátrica } \\
\text { depressão e ansiedade, há um ano de proposta terapêutica no CAPS-ad, solteira, mãe } \\
\text { de } 1 \text { filho de } 7 \text { anos, tem Ensino Fundamental completo, diz não ter religião, não } \\
\text { estava trabalhando naquele momento da entrevista e reside no DF com o filho e pais. } \\
\text { Já teve ideação suicida uma vez e refere que sofreu violência verbal por parte da } \\
\text { sobrinha. Iniciou o uso do álcool aos } 18 \text { anos, tem histórico de internação no CAPS- } \\
\text { ad uma vez. Faz uso de antidepressivo, anticonvulsivante e estabilizador de humor. } \\
\text { Sintomas de depressão moderada (BDI) e ansiedade leve (BAI). }\end{array}$ \\
\hline
\end{tabular}

Fonte: Dados do estudo

Em relação ao questionário fechado, contendo as perguntas do desenho sobre o desenho ("Metáfora da Chuva"), foram obtidos como resultado os quatro aspectos apresentados no Gráfico 1.

Gráfico 1: Frequência das respostas do questionário fechado sobre o desenho ("Metáfora da Chuva") inventário estruturado realizado com as mulheres dependentes de drogas participantes da pesquisa. Brasília, DF, Brasil, 2020. (n=28);

\section{Resultado do Questionário sobre o desenho "Metáfora da Chuva"}

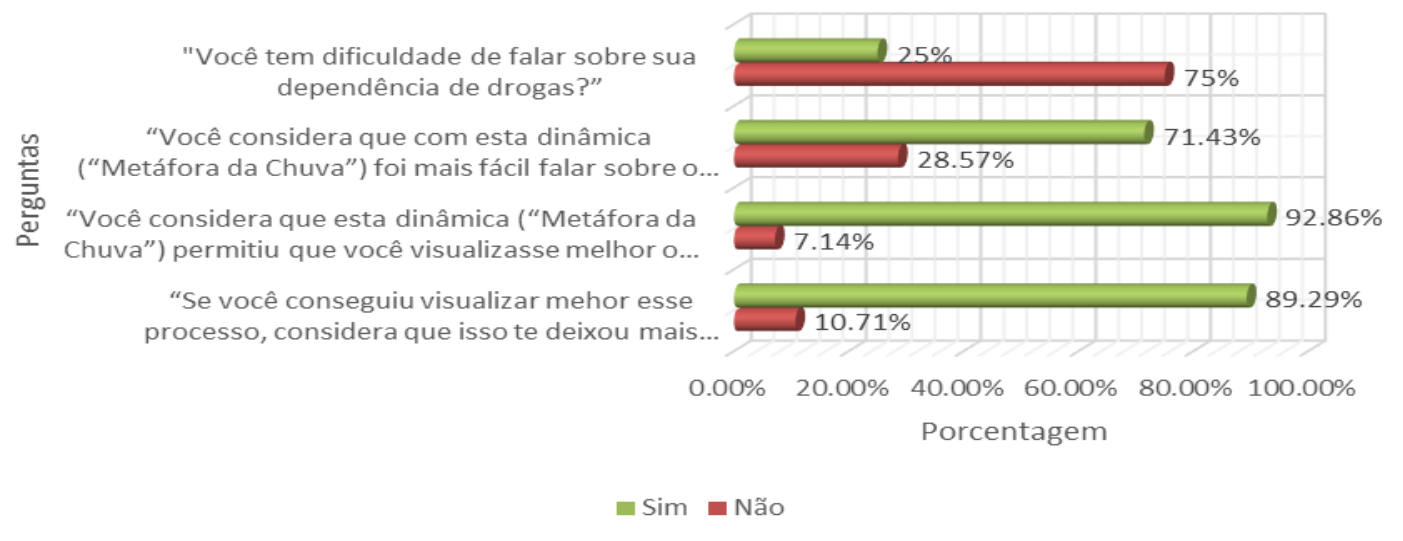

Fonte: Dados do estudo 
O resultado do questionário sobre o desenho "Metáfora da chuva" mostrou que vinte e uma (75\%) mulheres alegaram não ter dificuldade de falar de sua dependência de drogas. Em contrapartida, vinte (71,43\%) delas consideraram que por meio da dinâmica ("Metáfora da Chuva") foi mais fácil falar sobre sua dependência de drogas, vinte e seis $(92,86 \%)$ mulheres consideraram que a dinâmica permitiu que elas visualizassem melhor o processo da dependência: causas e consequências, bem como vinte e cinco $(89,29 \%)$ das mulheres conseguiram visualizar melhor esse processo de adoecimento e que as deixou mais seguras e confiantes para continuar o tratamento.

Nesse sentido, o desenho representado pela "Metáfora da Chuva” proporcionou às participantes a reflexão sobre a dimensão das causas, impacto e enfrentamento do transtorno sobre seus padrões de vida. Isso porque o referido desenho traduz em uma página (imagem) a representação simbólica resumida do processo de adoecimento pelas drogas. Ademais, o desenho pode fomentar nas mulheres as habilidades de compreender e resolver seus problemas decorrentes do abuso de drogas, bem como favorecer o vínculo positivo com os terapeutas, por ser uma ferramanta lúdica e de fácil manipulação.

No artigo de Andrade e Veloso ${ }^{(34)}$, o uso de linguagem artística no contexto da saúde mental, espeficicamente em um CAPS na Paraíba, estimulou a autonomia e o protagonismo social dos participantes, que reconheceram um lugar na criação. Acrescentam Skeffington e Browne ${ }^{(35)}$, ao aplicarem imagens em Arteterapia para exploração de uma história de trauma intrafamiliar resistente e complexo de uma mulher australia alcoolista, perceberam que isso ajudou no tratamento e na superação da prevenção terapêutica.

Para Reis ${ }^{(36)}$, a Arteterapia emprega produção artística em prol da saúde mental e da qualidade de vida. Coqueiro, Vieira e Freitas ${ }^{(37)}$ observaram que a Arteterapia possibilitou aos usuários a vivência de suas dificuldades, medos, conflitos e angústias e notaram que a Arteterapia é um instrumento eficaz para a canalização das variáveis do adoecimento mental, dos conflitos pessoais e familiares. Complementa Reis ${ }^{(36)}$ que a arte é um meio importante de expressão da subjetividade humana e permite ao profissional da saúde e a seu cliente alcançar conteúdos presentes no inconsciente, desde traumas e conflitos aos aspectos das relações interpessoais e expectativas profissionais, e reorganizá-los por meio da atividade artística.

Valladares-Torres ${ }^{(38)}$ ao utilizar o desenho em várias atividades com dependentes de drogas observou que ele possibilitou uma avaliação diagnóstica, no qual os participantes expuseram suas vulnerabilidades, seus fatores de proteção, seu movimento energético e o aparecimento de algumas demandas, além de auxiliar no o autoconhecimento e a catarse de emoções. Complementam Venkatesan e Peter $^{(39)}$ que o desenho é uma forma catártica de expressão e é, frequentemente, utilizado tanto para ajudar na técnica de narração quanto como um exercício terapêutico em contextos clínicos. Ao analisar 
cenas de desenho em memórias de medicina gráfica selecionadas, os autores mostram como o ato de desenhar facilita a autorrecuperação e auxilia pacientes ou indivíduos traumatizados a resolver seu caos por meio da expressão criativa. O desenho, como técnica expressiva em Arteterapia, pode ajudar na ordenação e na estruturação psíquica, bem como na conscientização de símbolos ocultos, desconhecidos ou reprimidos da psique humana e auxiliar no autoconhecimento e na reabilitação dos toxicômanos ${ }^{(40)}$.Essa ideia é ancorada em outro estudo qualitativo realizado com 26 presidiárias utilizando-se a técnica projetiva de desenho-história com o tema drogas, cuja análise foi fundamentada na Teoria das Representações Sociais e evidenciou nos grafismos e conteúdo das histórias o sofrimento psíquico e a agressividade, objetivadas e respaldadas nas dimensões afetiva, comportamental e psicossocial das participantes. $\mathrm{O}$ envolvimento das mulheres com as substâncias psicoativas, na tentativa de reconhecimento social e superação de carências afetivas, gerou rebaixamento da estima, retraimento e isolamento $^{(41)}$.

Somente pela dimensão singular da escuta qualificada é que os profissionais de saúde podem oferecer ajuda a cada mulher que abusa das substâncias psicotrópicas; o processo permitirá desvelar a importância que cada uma coloca a substância na sua vida ${ }^{(42)}$.

\section{CONSIDERAÇÕES FINAIS}

Por meio do desenho "Metáfora da chuva" realizado neste estudo, foi possível conhecer o processo de adoecimento, sob a ótica de mulheres dependentes de substâncias psicoativas e que estavam em proposta terapêutica no CAPS-ad III. Da mesma forma, pela pesquisa foi possível traçar o perfil sociodemográfico, clínico e psiquiátrico e investigar a prevalência de sintomas depressivos e ansiosos dessas mulheres, que auxiliaram no diagnóstico das comorbidades associadas e na compreesão da complexidade do problema.

Os desenhos "Metáfora da chuva" desenvolvidos pelas mulheres permitiram elucidar uma trajetória de vida subjetiva permeada por muitas fragilidades e vulnerabilidades pelo seu próprio protagonismo. Para tanto, a oferta de um espaço para o diálogo e a reflexão, no sentido de proporcionar momentos de elaboração de experiências negativas, pode ser uma oportunidade de reconstrução de novos projetos de vida. Nesse sentido, é pertinente a inclusão dessa atividade como prática de cuidados em saúde mental, em especial da enfermagem, a fim de facilitar o tratamento e reabilitação delas.

Atualmente, com a reforma psiquiátrica, formas criativas e inovadoras nos cuidados voltados para pessoas com transtornos mentais são fundamentais, uma vez que favorecem o vínculo afetivo positivo, bem como facilitam o tratamento, visto que esse público, frequentemente, tem dificuldade de compreeder o seu adoecimento pelos caminhos tradicionais. 
Ao compreender o processo de adoecimento por parte dos profissionais de saúde, em especial dos enfermeiros, que podem, por meio da dinâmica do desenho representado pela "Metáfora da Chuva", facilitar a promoção da integração entre cuidado e cuidador. Pois conhecer o processo de adoecimento na perspectiva do doente pela arte, direciona o foco de cuidado conforme a singularidade de cada mulher e de maneira mais rápida. $\mathrm{O}$ desenho favorece que se tragam as demandas das mulheres de com mais eficácia, do que somente a verbalização de suas necessidades. Nessa conjuntura podem tornar as mulheres mais protagonistas da construção do seu projeto de vida no CAPS-ad, uma vez que facilitam o compartilhamento de responsabilidades e a construção mais efetiva de cuidados de acordo com as particularidades de cada uma.

Por outro lado, o processo de adoecimento é complexo e é permeado pela singularidade de cada sujeito inclusive pelas questões de gênero, além do que, o desenho representado pela "Metáfora da Chuva" deu maior visibilidade às demandas do universo feminino. Dessa forma, ressalta-se a importância de utilizar desenho representado pela "Metáfora da Chuva" ou a criação de técnicas criativas e inovadoras que privilegiem, em especial, os cuidados voltados para o público feminino no contexto das toxicamanias, como coadjuvante no tratamento.

\section{REFERÊNCIAS}

1. SNPD - Secretaria Nacional de Políticas sobre Drogas. Efeitos de substâncias psicoativas. 11. ed. Brasília: SENADE, 2017. Módulo 2.

2. ONU - ORGANIZAÇÃO DAS NAÇÕES United Nations Office for Drugs Control and Crime. World Drup Report 2015. New York: United Nation Publication, 2015.

3. Brasil. Ministério da Saúde. Portaria n $n^{\circ}$ 3.088, de 23 de dezembro de 2011. Institui a rede de atenção psicossocial para pessoa com sofrimento ou transtorno mental e com necessidades decorrente do uso de álcool, crack e outras drogas, no âmbito do SUS. Brasília, 2011.

4. Souza AC, Guljor APF, Silva JLL. Refletindo sobre os centros de atenção psicossocial. Rev. Av. Enferm. 2014; 32(2):292-98.

5. Valladares-Torres ACA, Rodrigues LTA. Eficácia de programa de Arteterapia com grupo de mulheres com dependência de drogas. Revista de Arteterapia Proceso Creativo Transformación. 2020; (7):50-6. Disponible en: www.arteterapiarevista.com.ar

6. Angelim SMAV, Valladares-Torres ACA. O desenho "metáfora da chuva" como instrumento de comunicação terapêutica da problemática drogadição. Rev Cient Artt Cores Vida. 2019; 26(1):48-57. Disponível em: https://www.abcaarteterapia.com/revista-cores-da-vida 
7. Beck AT, Ward C, Mendelson M. Beck Depression Inventory (BDI). Arch Gen Psychiatry. 1961; 4:561-71.

8. Beck AT, Steer RA, Brown G. Beck anxienty checklist. Unpublished manuscript, University of Pensylvania, 1985.

9. Bardin L. Análise de conteúdo. Lisboa, Portugal: Edições 70 - Brasil: edição revista e ampliada; 2011.

10. Pillon SC, Santos MA, Florido LM, Cafer JR, Ferreira OS, Scherer ZAP, Marchini GPO. Consequências do uso de álcool em mulheres atendidas em um Centro de Atenção Psicossocial. Rev Eletr Enf [Internet]. 2014; 16(2):338-45. Disponível em: http://dx.doi.org/10.5216/ree/v16i2/22712

11. Mastroianni FC, Macris CE, Gomes JR, Camargo PJ. Perfil sociodemográfico de um CAPSad e sua funcionalidade segundo os usuários. Rev. Psicol. Saúde. 2016; 8(2): 3-16.

12. Danieli RV, Ferreira MBM, Nogueira JM, Oliveira LNC, Cruz EMTN, Araújo Filho GM. Perfil sociodemográfico e comorbidade psiquiátricas em dependentes químicos acompanhados em comunidades terapêuticas. J Bras Psiquiatr. 2017; 66(3):139-49.

13. Oliveira VC, Capistrano FC, Ferreira ACZ, Kalinke LP, Felix JVC, Maftum MA. Sociodemographic and clinical profile of people assisted in a CAPS ad in the South of Brazil. Rev Baiana Enferm, 2017; 31(1)e16350:1-10.

https://portalseer.ufba.br/index.php/enfermagem/article/view/16350/14060

14. Bettarello VC, Silva LMA, Molina NPFM, Silveira T, Rodrigues LR. Quality of life, spirituality, religion and personal beliefs of chemical dependents in treatment. Rev. Eletr. Enf. [Internet]. 2016; 18:e1194. Available from: https://revistas.ufg.br/fen/article/view/41677/22102

15. Silva ML, Guimarães CF, Salles DB. Risk and protective factors to prevent relapses of psychoactive substances users. Rev Rene. 2014; 15(6):1007-15. Available from: http://periodicos.ufc.br/rene/article/view/3302/2541

16. Macagnan JP, Menetrier JV, Bortoloti DS. Perfil dos usuários de um Centro de Atenção Psicossocial no município de Francisco Beltrão - Paraná. Biosaúde. 2014; 16(2):34-44. Disponível em: http://www.uel.br/revistas/uel/index.php/biosaude/article/view/24354/17933

17. Pereira IS. Produção científica no Brasil sobre álcool e mulher: uma revisão bibliográfica. Serviço Social em 2012; Revista. 14(2):236-41. Disponível em: http://www.uel.br/revistas/uel/index.php/ssrevista/article/view/11615/11646

18. Laranjeira R. et al. II Levantamento Nacional de Álcool e Drogas (LENAD) - 2012. Instituto Nacional de Ciência e Tecnologia para Políticas Públicas de Álcool e Outras Drogas (INPAD), UNIFESP. São Paulo: 2014.

19. Andretta I, Limberger J, Schneider JA, Mello LTN. Sintomas de depressão, ansiedade e estresse em usuários de drogas em tratamento em comunidades terapêuticas. Psico USF. 2018; 23(2):361-73. 
20. Siqueira DF, Terra MG, Soccol KLS, Canabarro JL, Moreschi C. Reasons attributed by users seeking treatment in a psychosocial care center alcohol and drugs. REME - Rev. min. Enferm. 2018; 22:e-1082:17. Available from: http://www.reme.org.br/artigo/detalhes/1220

21. Freire AKS, Melo MCP, Carvalho MFAA, Melo RS, Limeira CG. Configurações e dinâmicas familiares de mulheres-mães durante trajetória na dependência química. Cienc. enferm; 2016; 22(2):5162.

22. Pereira VCLS, Andrade FA, Espínola LL, Azevedo EB, Nogueira JA, Ferreira Filha MO. Psychological distress in adolescents associated with family alcoholism: possible risk factors. Rev. Eletr. Enf. [Internet]. 2015; 17(2):178-85.

23. Soares LCO, Ruzzi-Pereira A, Pereira PE, Souza ACA, Andrade VS. Papéis ocupacionais de mulheres que fazem uso abusivo de substâncias psicoativas. Rev Ter Ocup Univ. 2013; 24(3):199-207.

24. Lucchese R, Caixeta FC, Silva YV, Vera I, Felipe RL, Castro PA. History of violence against women living with alcohol and drug abuse. Rev. enferm. UFPE on line. 2017; 11(supl.9):3623-31. Available from: https://periodicos.ufpe.br/revistas/revistaenfermagem/article/view/234505/27718

25. Silva Júnior FJG, Tolentino ES, Oliveira AKS, Monteiro CFS. Chemical dependency and violence in the female universe: an integrative review. Rev. pesqui. cuid. fundam. (Online). 2016; 8(3):4681-8.

26. Fertig A, Schneider JF, Oliveira GC, Olschowsky A, Camatta MW, Pinho LB. Women crack users: knowing their life stories. Esc. Anna Nery Rev. Enferm. 2016; 20(2):310-16.

27. Dagnoni JM, Garci A. Dependência química, amizade e desenvolvimento humano. Gerais, Rev. Interinst. Psicol. 2014; 7(1):17-26.

28. Medeiros KT, Maciel SC, Sousa PF, Vieira GLS. Vivências e representações sobre o crack: um estudo com mulheres usuárias. Psico-USF. 2015; 20(3):517-28.

29. Prochaska JA, DiClemente CC, Norcross JC. In search of how people change: applications to addictive behaviour. Am Psychol. 1992; 47(9):1102-14.

30. Nascimento VF, Moll MF, Lemes AG, Cabral JF, Cardoso TP, Luis MAV. Percepção de mulheres em situação de dependência química no interior de Mato Grosso, Brasil. Cult. Cuid. 2017; 21(48):33-42.

31. Melo JRF, Maciel SC. Representação social do usuário de drogas na perspectiva de dependentes químicos. Psicol. cienc. prof. 2016; 36(1):76-87.

32. Ferreira ACZ, Czarnobay J, Borba LO, Capistrano FC, Kalinke LP, Maftum MA. Functionality comparison of elderly residing in two institutional modalities. Rev. Eletr. Enf. [Internet]. 2016; 18(1):e1144. Available from: http://dx.doi.org/10.5216/ree.v18.34292

33. Guerra MRSR, Vandenberghe L. Abordagem do comportamento de uso abusivo de substâncias psicoativas no Brasil: o estado da arte. Pesquisas e Práticas Psicossociais. 2018; 13(1):e1120.

34. Andrade LA, Veloso TMG. Arte e saúde mental: uma experiência com a metodologia participativa da Educação Popular. Pesquisas e Práticas Psicossociais. 2015; 10(1):79-87. 
35. Skeffington PM, Browne M. Art therapy, trauma and substance misuse: using imagery to explore a difficult past with a complex client. International Journal of Art Therapy. 2014; 19(3):114-21.

36. Reis AC. Arteterapia: a arte como instrumento de trabalho do psicólogo. Psicologia: Ciência e Profissão. 2014; 34(1):142-57.

37. Coqueiro NF, Vieira FRR, Freitas MMC. Art therapy as a therapeutic tool in mental health. Acta Paul Enferm. 2010; 23(6):859-62.

38. Valladares-Torres ACA. A Arteterapia como dispositivo terapêutico no acolhimento integral das toxicomanias. Rev Artt AATESP. 2017; 8(1):38-56.

39. Venkatesan S, Peter AM. 'I want to live, I want to draw': the poetics of drawing and graphic medicine. Journal of Creative Communicationsv. 2018; 13(2):1-19. Available from: https://journals.sagepub.com/doi/abs/10.1177/0973258618761406?journalCode=crca

40. Fernades MC, Valladares-Torres ACA, O desenho como terapia e elucidação de sonhos com usuários de um Centro de Atenção Psicossocial-álcool e outras drogas do Distrito Federal. Rev Científica Arteterapia Cores da Vida. 2019; 26(2): 17-24. Disponível em: https://www.abcaarteterapia.com/revistacores-da-vida

41. Rodrigues S, Porcino CA, Reale MJOU. Imaginary of female prisoners about the phenomenon of drugs Rev. Eletr. Enf. [Internet]. 2016; 18(e1154):1-11. Available from: https://revistas.ufg.br/fen/article/view/31072/21205

42. Carrilho CA, Silveira LC, Martins IC, Dantas RA. Improper use of psychotropic substances amongst women: a study based on the female singularity. REME rev. min. Enferm. 2015; 19(3):664-80. 